\title{
ANNOTATIONS
}

\section{The International Congress and Ophthalmic Literature}

The suggestion made by the Council of International Ophthalmological Congresses that all ophthalmic journals should publish in each issue the titles of the original articles appearing in all other ophthalmic journals is one that, if carried out efficiently, should be of considerable assistance to all students of ophthalmic literature. A scheme of this nature was attempted some years ago by the Ophthalmic Review, now merged with this journal, but fell through on account of the labour involved. This difficulty would be considerably reduced if all journals would agree with a proposal made to this journal by Dr. Morax, the editor of the Annales d'Oculistique. He proposes to exchange with each issue a proof of the contents of the two journals. This we have arranged to do, and would be very glad to make a similar exchange with any other ophthalmic journals willing to co-operate.

\section{Colour Vision}

On page 633 of this number of the journal we publish the Report of a Committee of the British Association upon Colour Vision- "with particular reference to the classification of Colourblindness." We venture to express the opinion that no goodand possibly positive harm-is done by dogmatic statements such as are contained in this report, especially when issued under the aegis of a great society of acknowledged scientific prestige. Destructive criticism is little to our taste, unless it takes the form of further scientific investigation and research; but, lest silence should be interpreted as giving consent, reasons must be adduced for an adverse verdict. We shall mention only a few.

Thus, paragraph 1 is probably true, but it has not been proved, and there are cases which have been held by competent observers to indicate the opposite. Is it then a reform to introduce a new nomenclature which may prove as faulty as the old? In the present state of ignorance, if paragraph 2 is accepted-"one must know the actual differences in colour discrimination between normal and hypochromatic individuals"- the quest is vain for it is an as yet unattained counsel of perfection. Paragraphs 4 to 6 conform to the principle that it is well to be off with the old love before one is on with the new, but unless the individual's reasoning capacity is submerged by the waves of emotion he will first decide that the new is better than the old. The old terms 